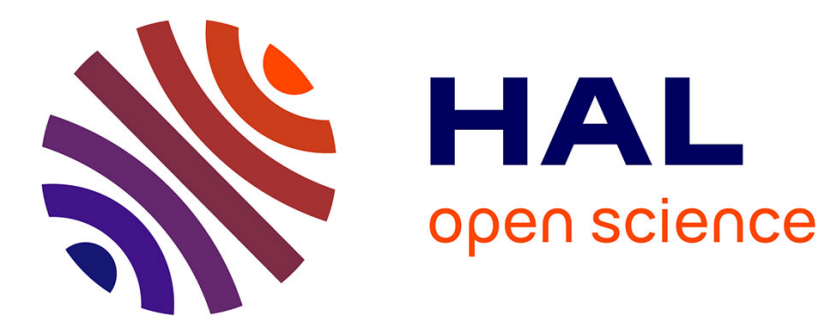

\title{
Optimal Taxation to Correct Job Mismatching
} Guillaume Wilemme

\section{To cite this version:}

Guillaume Wilemme. Optimal Taxation to Correct Job Mismatching. 2017. halshs-01531309

\section{HAL Id: halshs-01531309 \\ https://shs.hal.science/halshs-01531309}

Preprint submitted on 1 Jun 2017

HAL is a multi-disciplinary open access archive for the deposit and dissemination of scientific research documents, whether they are published or not. The documents may come from teaching and research institutions in France or abroad, or from public or private research centers.
L'archive ouverte pluridisciplinaire HAL, est destinée au dépôt et à la diffusion de documents scientifiques de niveau recherche, publiés ou non, émanant des établissements d'enseignement et de recherche français ou étrangers, des laboratoires publics ou privés. 


\section{amse}

école d'économie d'aix-marseille

aix-marseille school of economics

\section{Working Papers / Documents de travail}

\section{Optimal Taxation to Correct Job Mismatching}




\title{
Optimal Taxation to Correct Job Mismatching*
}

\author{
Guillaume Wilemme ${ }^{\dagger}$
}

JUNE 2017

\begin{abstract}
This paper presents a new efficiency argument for an accommodating taxation policy on high incomes. Job seekers, applying to different segments of a frictional labor market, do not internalize the consequences of mismatch on the entry decision of firms. Workers are not selective enough, resulting in a lower average job productivity and suboptimal job creation. The output-maximizing policy is antiredistributive to improve the quality of the jobs prospected. As an income tax affects the sharing of the match surplus, a tax on production (or profits) is required to redress the slope of the wage curve. Neither a minimum wage nor unemployment benefits can fully decentralize optimal search behaviors.
\end{abstract}

JEL Code: H21, H23, J24, J42

Keywords: anti-redistributive taxation, composition externality, job quality, mismatch, search strategy

*I am particularly thankful to Etienne Lehmann for his guidance. I am also grateful to Alexandre De Cornière, Bruno Decreuse, Fabien Postel-Vinay, Bruno Van der Linden and Etienne Wasmer for their helpful comments.

${ }^{\dagger}$ Aix-Marseille Univ., CNRS, EHESS, Centrale Marseille, AMSE. Mail: research@gwilemme.com 


\section{Introduction}

The public finance literature insists on the efficiency loss from taxing the most able or productive individuals. High-ability workers might adjust to taxes by reducing their labor supply more strongly than low-ability workers. Accordingly, taxation should accommodate for the top levels of income distribution. This theoretical result derives from crucial assumptions about individual preferences, namely that individuals choose to work more as they are more able. The present paper proposes a new mechanism arguing for a reduced fiscal pressure on high incomes. The mechanism is based on job search behaviors, a much less explored margin than the traditional labor supply behaviors.

The economic mechanism in this article relies on a general equilibrium effect which connects workers' search strategies to firms' decisions to create jobs. When searching for a job, workers find a trade-off between immediately seizing a job offer or waiting for a better job. How selective job seekers are then determines the extent of mismatch on the labor market. The misallocation of workers and firms, which is related to the productivity of jobs, has direct consequences on the job opening decisions of firms. Less mismatch leads to more job openings because firms' profits increase with the average productivity of jobs. By not internalizing job creation decisions, workers are not selective enough and thus job quality is diminished. In this context, taxing high-productive jobs (or employed workers) reinforces this composition externality by reducing the gains from selectivity. Abstracting from equity concerns, the optimal self-financed taxation is antiredistributive: it taxes low-quality jobs and it subsidizes high-quality jobs to foster job seekers' selectivity.

The model requires three main hypotheses to produce this result: search frictions and random matching, segmentation of the labor market per jobs' type, and symmetric comparative advantages. Job mismatch occurs when a reallocation of workers across firms can improve the matching of workers' abilities with firms' technology. Some firms do not employ the most suitable workers and, conversely, some workers would be more productive with another employer. Mismatch does not arise without frictions on the labor market. The model adopts the convenient framework of Diamond-Mortensen-Pissarides (see Pissarides 2000 for an overview), in which search frictions prevent instantaneous matching between firms and workers. As a departure from this standard model, the labor market is assumed to be segmented by firms' type. Workers then choose a search effort for each type of firm and match randomly with employers. Such a segmentation of the labor market is the cause of a composition externality. Mismatch is in this way inefficient, meaning not constrained Pareto-optimal given the search frictions. The model abstracts from any vertical heterogeneity among workers or firms to insist on the role of pure mismatch. The two-sided heterogeneity is accordingly modeled à la Salop (1979). The distance between a worker and her employer on the Salop's circle is a sufficient statistic of the job's productivity. Workers have thus symmetric comparative advantages in producing across the firms' types. Vertical heterogeneity would introduce an additional departure from efficiency due to complex search externalities as identified by Shimer and Smith (2001). The focus of 
the paper is on the inefficient allocation of workers and firms, essentially a problem of comparative advantages and horizontal heterogeneity. The model is a limit case in which risk aversion and any equity objective of the government are ignored. Optimal taxation consists in a self-financed Pigouvian tax that simply restores efficiency. The results in this paper, however, provide insights on how the trade-off between equity and efficiency would be affected by inefficient job mismatch. The efficiency loss of a given redistributive policy is weighted down in presence of inefficient mismatch.

The first contribution is to show that the output-maximizing policy relies on antiredistributive taxation. By redistributing from low-quality to high-quality jobs, the government provides workers with the incentives to focus their search efforts on the most suitable jobs. This redistribution cannot be achieved by the sole use of income taxes. The fiscal authority fixes a proportional tax on wages and a lump-sum tax, but also a proportional tax on production. On the one hand, job seekers and employers create search externalities on the labor market as in the standard search and matching framework. An optimal quantity of jobs created is guaranteed when the Hosios-Pissarides condition is satisfied (Hosios, 1990; Pissarides, 2000): the match surplus is split according to the externalities created by each side of the market. The wage tax is necessary to maintain this condition in the decentralized equilibrium. On the other hand, the wage curve as a function of productivity must be steeper for job seekers to choose the right search strategies. The tax on production (or profits) aims at redressing the wage curve to restore an optimal quality of jobs. As a robust result, the optimal tax parameters are independent of the search technology, the matching function and the production function.

The second contribution investigates the room for other public policies. Neither a minimum wage, a subsidy to job creation nor an increase in unemployment benefits enable private agents to internalize the composition externality. These three policies can help workers stop applying for low-quality jobs. The composition externality, however, still remains because workers modulate their search efforts such that high-quality jobs are under-prospected. As long as these policies do not improve the slope of the wage curve, they are insufficient to restore optimality. In addition, neither is non-linear income taxation sufficient to decentralize the optimum without a tax on production or on profits. Income taxation modifies the wage bargaining within the match. For this reason, the tax authority forfeits the income tax tool to insure an optimal surplus sharing between any employee and her employer.

The third contribution is a reasonable simulation of the model to measure the welfare gap between the social optimum and the decentralized equilibrium without taxation. In the most parsimonious simulations, social welfare, or equivalently total net output, is lower by 1 to $7 \%$ at the decentralized equilibrium relative to the social optimum. Providing the right incentives requires heavy taxation with tax rates higher than $100 \%$ in some cases, compensated by lump-sum taxes or subsidies. Far from being a policy recommendation, these calibrated tax rates are insightful as a measure of the distance between the decentralized equilibrium and the social optimum. 
This paper belongs to the literature on the efficiency of markets with search frictions. The pioneer work of Mortensen (1982) demonstrates that the sharing of the joint production in the mating game affects the players' incentives to exert efforts. As a player searches more intensively, it increases not only her own meeting probability but also the other player's. Players, however, do not in general internalize this positive externality. Hosios (1990) and Pissarides (2000) more precisely focus on this inefficiency in the search and matching framework with Nash bargaining. They show that the inefficiency disappears only in a particular context in which the matching technology has constant returns to scale and the bargaining power equals the elasticity of the matching function. Some research explores heterogeneity as a departure from the standard framework. Lockwood (1986) identifies inefficient job-acceptance decisions in presence of vertical heterogeneity. Shimer and Smith (2001) deal with heterogeneous agents who choose a search intensity and a matching strategy. Because of this heterogeneity, the positive and negative externalities induced by the search efforts cannot compensate. The high-productive agents do not search enough contrary to the low-productive ones who search too much. In the same spirit as Mortensen (1982), a high-productive agent who searches more increases the probability of the others to find a productive match. Conversely, the low-productive agents reduces the expected match quality. Their setting do not account for the endogenous entry of firms. On the contrary, the mechanism at the core of the present paper extensively relies on this job creation condition. Other works by Acemoglu (2001), Charlot and Decreuse (2005) and Uren (2006) highlight the possible externalities resulting from this general equilibrium channel with vertical heterogeneity. The present article meanwhile focuses on horizontal heterogeneity and comparative advantages as with Marimon and Zilibotti (1999) and Decreuse (2008). The theoretical framework borrows from the article by Decreuse (2008) to obtain original results about optimal taxes and public policies.

This paper also belongs to the literature on taxation in frictional markets. Pissarides (1985, 1998) and Lockwood and Manning (1993) investigate the impact of taxes in a positive approach. They analyze how labor income taxation affects wage bargaining between workers and firms. Boone and Bovenberg (2002) adopt a normative approach and find the optimal wage tax to decentralize efficient bargaining, namely the HosiosPissarides condition, in the standard search and matching framework. The present paper extends their result to account for a degree of heterogeneity and market segmentation. In addition to dealing with the classical search externalities, the optimal tax scheme in this paper rules out the composition externality at the base of inefficient mismatch. The results go in the same direction as Amine and Santos (2008). They insist on the impact of negative income taxation on job seekers' selectivity, which could have detrimental effect on firms' technical choices. Hungerbühler et al. (2006) explore the optimal income taxation on labor markets with search frictions when society values equity. They assume, however, completely segmented labor markets per type and exogenous search. This paper focuses precisely on the theoretical implication of such an assumption. Optimal taxation for mismatch here echoes the positive result of Acemoglu (2001). He shows that public 
policies aiming at increasing job seekers' selectivity can reduce the excessive creation of "bad jobs".

The structure of the paper is as follows. The first section defines the theoretical framework and the main hypotheses. The second section presents the main result of the paper regarding optimal taxation. A third section explores other public policies, and show that they cannot fully decentralize the social optimum. The model is then calibrated in a fourth section before concluding.

\section{The search and matching framework}

This section introduces the theoretical model. First, the functioning of the labor market is defined through mathematical notations. Second, the optimal search strategies and optimal level of job creation are characterized in Definition 1. In the third part, the decentralized equilibrium is defined and Proposition 1 describes the optimum-decentralizing wage profile. The last part studies the decentralized equilibrium in presence of taxation and Nash-bargained wages.

\subsection{The plot}

The model of the labor market accounts for two-sided heterogeneity and comparative advantages, following Decreuse (2008). Time is continuous. A measure 1 of infinitelylived and risk-neutral workers is endowed with one inexhaustible and indivisible unit of labor. On the other side of the labor market, firms post vacancies to recruit workers. They can employ no more than one worker. ${ }^{1}$ A firm is then equivalent to a vacancy, open or filled, and the terms will be used interchangeably. A worker's type corresponds to her endowment in specific skills. Symmetrically, a firm's type represents its requirements in skills. The productivity of each job depends on the match between the employee's skills and the firm's requirements. Following Salop (1979), a type is a location on a circle of perimeter 1 . The job productivity $y(x)$ depends only on the distance $x$ between the firm and the worker on the circle. Workers are uniformly and continuously distributed over the circle. $^{2}$ Same-type firms define a sector or an industry. Absolute advantages are removed from the analysis from the symmetry property of the model. Workers merely differ in the sectors in which they are productive. The function $y$ is defined from $\left(0, \frac{1}{2}\right)$ into $\mathbb{R}^{+}$. It is differentiable and strictly decreasing, meaning workers are less productive when matched with a more distant firm. For each sector, a share $2 x$ of workers has a productivity of at least $y(x)$, for any $x$ between 0 and $1 / 2$.

Each sector constitutes a segment of the labor market on which recruiters and applicants meet. Recruiters are same-sector firms with a vacant position whereas applicants

\footnotetext{
${ }^{1}$ This is equivalent to assuming constant returns to scale in firms' production technology and searching activities.

${ }^{2}$ One can also consider an infinite line or a discrete distribution of types as long as symmetry is respected. See Salop (1979).
} 
can be unemployed workers of any type. Search frictions prevent the instantaneous matching of firms and workers. Some matches can be imperfect in the sense that the distance in the skill space between the employer and the employee is nonzero. ${ }^{3}$ By incurring a search $\operatorname{cost} \xi_{0}$, a job seeker multiplies his baseline job-finding rate $m$ on a sector by an efficient search intensity $S\left(\xi_{0}\right)$, where $S$ is twice differentiable, increasing and concave. The search technology has decreasing returns to scale at the location level: the more a worker searches on a particular sector, the less she multiplies her job-finding rate. No effort produces a nil search intensity, $S(0)=0$, and the marginal search intensity tends to infinity and to zero respectively as the effort tends to zero and to infinity, $\lim _{\xi_{0} \rightarrow 0} S^{\prime}\left(\xi_{0}\right)=\infty$ and $\lim _{\xi_{0} \rightarrow \infty} S^{\prime}\left(\xi_{0}\right)=0 .{ }^{4}$ A search strategy consists in choosing a search effort (expressed in cost units) for each segment of the labor market. For the sake of simplicity, the focus is on the symmetric steady state. Unemployed workers thus choose the same strategy, meaning the same mapping function $\xi$ from $\left(0, \frac{1}{2}\right)$ into $\mathbb{R}^{+}$with $\xi(x)$ as the search cost for jobs with distance $x$ in the skill space. Thanks to this symmetry assumption, firms endogenously create vacancies uniformly on the circle. ${ }^{5} \xi(x)$ is the search effort or cost, and $S(\xi(x))$ is the search intensity on a market at a distance $x$. A worker exerts an overall search effort $\xi^{T}$ and produces a total search intensity $S^{T}(\xi)$,

$$
\xi^{T}=2 \int_{0}^{\frac{1}{2}} \xi(x) d x, \quad S^{T}(\xi)=2 \int_{0}^{\frac{1}{2}} S(\xi(x)) d x .
$$

The baseline job-finding rate $m$ is identical across worker types. It is endogenoulsy determined by a matching technology in the spirit of Diamond-Mortensen-Pissarides. ${ }^{6}$ There is a measure $u$ of unemployed workers of each type. A segment of the labor market is then made of $S^{T}(\xi) u$ of applicants, expressed in efficiency units. The number of vacancies per sector is denoted $v$. The measure of new meetings on a segment of the labor market is $M\left(S^{T}(\xi) u, v\right)$ with $M$ a Cobb-Douglas function with constant returns to scale. The elasticity of the meeting function relative to the measure of employers is denoted $\eta$ satisfying $0<\eta<1$. The baseline job-finding rate $m$ is a function of market tightness $\theta$, i.e. the ratio of the employers' mass to the efficient job seekers' mass,

$$
\theta=\frac{v}{S^{T}(\xi) u}, \quad m(\theta)=M(1, \theta)
$$

Consequently, the function $m$ is differentiable, strictly increasing and concave from $\mathbb{R}^{+}$ onto $\mathbb{R}^{+}$and $\eta=\frac{\theta m^{\prime}(\theta)}{m(\theta)}$. A worker exerting an effort $\xi(x)$ on a segment at a distance $x$ in the skill space meets a firm at the Poisson rate $S(\xi(x)) m(\theta)$. Conversely, a firm meets a

\footnotetext{
${ }^{3}$ See Shimer and Smith (2000) on the effects of search frictions on matching patterns.

${ }^{4}$ The model readily accommodates for a distance-specific search technology, namely $S$ as function of both the effort and the distance $x$. For instance, a same effort $\xi_{0}$ could further improve the job-finding rate for job seekers closer to a sector. The results for efficiency and optimal taxation are unaffected.

${ }^{5}$ See Decreuse (2008) for a detailed proof.

${ }^{6}$ See Pissarides (2000) for an overview.
} 
worker located at $x$ at the rate

$$
\frac{S(\xi(x))}{S^{T}(\xi)} \frac{m(\theta)}{\theta}
$$

This expression derives from the equality between the flow of workers and the flow of firms drawing a meeting at distance $x$ in the skill space. As a consequence, $q(\theta) \equiv \frac{m(\theta)}{\theta}$ is the rate at which a recruiter meets a worker unconditional on her type. Applications from a distance $x$ on a segment of the labor market can come from two locations, either the clockwise or the counterclockwise direction. The measure of meetings characterized by a distance $x$ is $\frac{2 S(\xi(x))}{S^{T}(\xi)}$. Workers can anticipate the job-acceptance decision, meaning the choice of each party to agree or not on matching after a meeting. They will never rationally pay a positive search cost for unsuccessful meetings. In other words, the optimal search strategy internalizes the job-acceptance margin; any meeting leads to a match. The expected value of a variable $A$ over the newly-created jobs for a given search strategy $\xi$ can be expressed

$$
\bar{A}(\xi)=\int_{0}^{\frac{1}{2}} A(x) \frac{2 S(\xi(x))}{S^{T}(\xi)} d x .
$$

Holding an open vacancy is costly, so that a finite measure of firms enters the market. The vacancy cost is denoted $k$. Once matched, firms pay employees a net transfer $w$ until the job breaks at an exogenous rate $s$, independent of the job's productivity. Time is discounted at a rate $r$ and financial markets are perfect.

\subsection{The social optimum}

Consider the inter-temporal problem of a benevolent social planner constrained by search frictions. ${ }^{7}$ The unemployment rate $u$ and the gross output $Y$ are two state variables. For a small time period $\Delta t$, a fraction $s \Delta t$ of employed workers lose theirs jobs and a fraction $S^{T}(\xi) m(\theta) \Delta t$ of unemployed workers are hired. Thus, the unemployment rate obeys the law of motion: $\dot{u}=s(1-u)-S^{T}(\xi) m(\theta) u$. To understand the dynamic of the gross output, one can focus on a change from $\xi^{\prime}$ to $\xi$. The distribution of job productivity does not adjust instantaneously. Matches break up at a rate $s$ and are replaced by jobs with mean productivity $\bar{y}(\xi)$. The arrival rate of these newly hired workers is $S^{T}(\xi) m(\theta) u$. The law of motion of the gross output is then $\dot{Y}=S^{T}(\xi) m(\theta) u \bar{y}(\xi)-s Y$. As agents are risk-neutral, the objective function is the production $Y$ net of the cost of vacancies $k S^{T}(\xi) \theta u$ and the cost of search activities $\xi^{T} u$. The planner's problem is

$$
\max _{\theta, \xi} \int_{0}^{\infty}\left[Y-k S^{T}(\xi) \theta u-\xi^{T} u\right] e^{-r t} d t \text { s.t. }\left\{\begin{array}{l}
\dot{u}=s(1-u)-S^{T}(\xi) m(\theta) u \\
\dot{Y}=S^{T}(\xi) m(\theta) u \bar{y}(\xi)-s Y
\end{array} .\right.
$$

Denote $\psi$ the social value of unemployment relative to the value of a job. This is defined as the ratio of the multipliers associated with the two dynamic constraints. $\psi$ is directly comparable to a productivity level and can be interpreted as the opportunity cost of being

\footnotetext{
${ }^{7}$ The unconstrained optimal allocation consists in full employment and no mismatch, workers hold a job in their most productive sector.
} 
hired immediately. The planner's problem reduces to a simple form.

Lemma 1 The planner's problem (1) characterizes the relative value of unemployment, $\psi$, as

$$
\psi=S^{T}(\xi) m(\theta)\left(\frac{\bar{y}(\xi)-\psi}{r+s}\right)-k S^{T}(\xi) \theta-\xi^{T}
$$

and the problem is equivalent to maximize this value:

$$
\max _{\theta, \xi}\left\{S^{T}(\xi) m(\theta)\left(\frac{\bar{y}(\xi)-\psi}{r+s}\right)-k S^{T}(\xi) \theta-\xi^{T}\right\} .
$$

A proof is given in appendix A. This result is equivalent to Proposition 1 of Acemoglu and Shimer (1999), which characterizes the efficient allocation of their model. At a rate $S^{T}(\xi) m(\theta)$, an unemployed is matched and the match yields a present-discounted net gain $\frac{\bar{y}(\xi)-\psi}{r+s}$. Jobs are more socially valuable when the discount rate and the separation rate are lower because individuals are more patient and jobs last longer. The two negative terms represent the vacancy cost per unemployed worker and the individual search cost.

A classical trade-off arises when fixing market tightness. On the one hand, workers match and start producing more rapidly when the labor market is tight for firms ("thickmarket externality"). The first term in the value of unemployment (2) is increasing in $\theta$. On the other hand, firms wait longer before meeting a worker and so they have to pay a higher expected vacancy cost ("congestion externality"). The second term is decreasing. The first-order condition relative to market tightness can be written as the balance between these negative and positive externalities at the margin,

$$
\frac{k}{q(\theta)}=\eta\left(\frac{\bar{y}(\xi)-\psi}{r+s}\right) \text {. }
$$

The expected vacancy cost on the left-hand side must be equal to the share $\eta$ of the expected match surplus, meaning the expected job productivity net of the unemployment value. The efficient search intensity satisfies the following first-order condition:

$$
\left\{\begin{array}{ll}
\xi(x)=0 & \text { if } \frac{y(x)-\psi}{r+s}-\frac{k}{q(\theta)} \leq 0 \\
S^{\prime}(\xi(x)) m(\theta)\left(\frac{y(x)-\psi}{r+s}-\frac{k}{q(\theta)}\right)=1 & \text { else }
\end{array} .\right.
$$

Jobs whose production is not high enough to compensate the value of unemployment and the expected vacancy cost together are not prospected. If the productivity of the worst feasible matches is too low, no search effort is exerted beyond a threshold distance in the skills space. This is true if a match at the other side of the Salop's circle has zeroproductivity, $y(1 / 2)=0$, for instance. As long as the net value of a match is positive, searching is efficient because the marginal gain from searching will be infinite at a zero level of efforts. The efficient strategy consists in searching until the marginal gain equalizes the marginal cost. As the marginal cost is 1 for any segment of the labor market, the 
marginal gains from searching equalize across segments. The optimal search strategy $\xi(x)$ is decreasing in $x$. In other words, workers have to search more for jobs whose productivity is higher.

Definition 1 An efficient allocation is characterized by a value of an unemployed worker $\psi$, market tightness $\theta$ and a search strategy $\xi$ fulfilling (2), (4) and (5).

The existence of an efficient allocation is proved as a particular case of a decentralized equilibrium in appendix B. An efficient allocation is not unique in general.

\subsection{Private agents' behavior}

Now, let us consider the behaviors of workers and firms, or more precisely their search strategies and job opening decisions at the steady state. The (net-of-tax) wage profile is considered exogenous in a first step. Let $W(x)$ be the worker present-discounted value of a match characterized by a distance $x$ in the skill space. When a worker meets a firm at a distance $x$, she makes a capital gain $W(x)-U$, with $U$ defined as the asset value of being unemployed. This quantity is the worker's surplus, once the job quality $y(x)$ is revealed to the worker and the firm. The surplus, however, is unknown before any meeting. It is in general different from the expected surplus, $\bar{W}(\xi)-U$, which is the expectation over the distribution of possible matches. When a worker is unemployed, she incurs the total search $\operatorname{cost} \xi^{T}$. She matches with a firm at the rate $S^{T}(\xi) m(\theta)$ and receives the expected surplus. The asset value of unemployment is accordingly defined by

$$
r U=-\xi^{T}+S^{T}(\xi) m(\theta)(\bar{W}(\xi)-U)
$$

The baseline model abstracts from unemployment benefits financed by taxation. This is the focus of a particular extension in section 3. When an employee works for a firm with a skill gap $x$, she earns the net-of-tax wage $w(x)$. She may return to the pool of unemployment if her match breaks, which occurs at a rate $s$. The asset value of a match satisfies

$$
r W(x)=w(x)+s(U-W(x))
$$

When matched, a worker misses the flow value of unemployment $r U$ until the job destruction. By definition, $\psi=r U$ in the decentralized equilibrium. Combining equations (6) and (7) provides an expression of the value of an unemployed worker:

$$
\psi=S^{T}(\xi) m(\theta)\left(\frac{\bar{w}(\xi)-\psi}{r+s}\right)-\xi^{T} .
$$

This characterization of the value of unemployment for workers differs from the social value defined in (2) in two respects. First, workers compare the expected wage to the value of unemployment, whereas the planner compares the expected output. Second, 
workers do not internalize the vacancy cost. Workers decide on their search strategy by maximizing their return in (8),

$$
\max _{\xi}\left\{S^{T}(\xi) m(\theta)\left(\frac{\bar{w}(\xi)-\psi}{r+s}\right)-\xi^{T}\right\} .
$$

The search effort then satisfies

$$
\begin{cases}\xi(x)=0 & \text { if } w(x) \leq \psi \\ S^{\prime}(\xi(x)) m(\theta)\left(\frac{w(x)-\psi}{r+s}\right)=1 & \text { else }\end{cases}
$$

When the labor income $w(x)$ is lower than the returns to unemployment $\psi$, the unemployed workers do not exert any search effort. ${ }^{8}$ If the value of a match from a worker's perspective is high enough, job seekers are willing to search until the marginal benefit equals 1.

From the perspective of the firms, $J(x)$ denotes the asset value of employing a worker with a skill gap $x$. Prior to meeting a worker, the expected value is $\bar{J}(\xi)$. Firms create jobs until reaching zero profit at the steady state. The no-arbitrage condition for free entry is the equality between the expected cost of holding a vacancy and the expected value of filling a vacancy. It can be expressed

$$
\frac{k}{q(\theta)}=\bar{J}(\xi)
$$

For the firm's side, the ex-post surplus of a $x$-type match $J(x)$ must be distinguished from the ex-ante surplus, $J(x)-\frac{k}{q(\theta)}$. The no-arbitrage condition restates as the expected ex-ante surplus to be equal to zero. When the employer meets a potential employee, however, she accepts the match as long as the ex-post surplus is positive, $J(x)>0$. In absence of precision, the surplus refers to the ex-post surplus as in the literature. The ex-ante surplus will always be accurately named. The vacancy cost is sunk before the meeting, and so it is not accounted for in the job-acceptance decision. A match yields a net flow profit $\pi(x)$ to the employer, with a risk to be broken at a rate $s$,

$$
r J(x)=\pi(x)-s J(x)
$$

The fiscal authority taxes production and labor income at rates $\tau_{y}$ and $\tau_{w}$. This tax scheme is equivalent to taxes on profits and labor incomes. For each job, the fiscal authority deducts $\tau_{y} y(x)+\tau_{w} w(x)$ and repays a lump sum $\tau_{y} \bar{y}(\xi)+\tau_{w} \bar{w}(\xi)$ so the fiscal revenue is nil in expectation. The taxation scheme is self-financed. The net flow profit can be written

$$
\pi(x)=\left(1-\tau_{y}\right) y(x)-\left(1+\tau_{w}\right) w(x)+\tau_{y} \bar{y}(\xi)+\tau_{w} \bar{w}(\xi) .
$$

\footnotetext{
${ }^{8}$ Actually, workers do not exert any effort either if $\pi(x)<0$ because the match would be rejected by the firm. It is implicitly assumed that $\pi(x)>0$ when $\frac{w(x)}{r+s}>\psi$ for the exogenous wage profile. Nash-bargained wages satisfy this condition.
} 
If the tax rates are positive, jobs whose productivity and wage are lower than their mean values receive a subsidy, whereas the productive and high-paying jobs are taxed. Notice the average job is not impacted directly by this redistribution effect: $\bar{\pi}(\xi)=\bar{y}(\xi)-\bar{w}(\xi)$. From equations (10) and (11), the total expected vacancy cost is equal to the presentdiscounted value of expected profits:

$$
\frac{k}{q(\theta)}=\frac{\bar{y}(\xi)-\bar{w}(\xi)}{r+s}
$$

The expected wage and market tightness are in a positive relationship. A higher wage reduces profits and so less firms decide to open vacancies. The expected wage can be substituted in the value of unemployment in (8) by incorporating the no-arbitrage condition for free entry (13),

$$
\psi=S^{T}(\xi) m(\theta)\left(\frac{\bar{y}(\xi)-\psi}{r+s}\right)-k S^{T}(\xi) \theta-\xi^{T}
$$

The term inside the big parentheses is the expected match surplus when an employee and an employer meet. The two negative terms on the right-hand side are the flow cost of vacancies per unemployed worker and the search cost. These are sunk before any meeting, which excludes them from the bargain. This equation defines how private agents value unemployment given the search behaviors and endogenous market tightness. From the free-entry condition, the expected wage is the residual of the expected productivity net of the vacancy cost. Consequently, the vacancy cost appears in this characterization even though workers do not internalize it when searching. The social planner and private agents actually value unemployment identically.

A value of an unemployed worker $\psi$, market tightness $\theta$ and a search strategy $\xi$ fulfilling equations (2), (13) and (9) defines an equilibrium given a wage profile. A comparison with the optimal allocation defined by (2), (4) and (5) is relevant before accounting for endogenous wages.

Proposition 1 The decentralized equilibrium is efficient if and only if the wage profile is such that firms obtain a share $\eta$ of the match surplus on expectation over the distribution of match types,

$$
\bar{y}(\xi)-\bar{w}(\xi)=\eta(\bar{y}(\xi)-\psi)
$$

and such that the present-discounted value of profits compensates the expected vacancy cost for each match, or equivalently the ex-ante firm's surplus is nil for each match:

$$
\frac{k}{q(\theta)}=\frac{y(x)-w(x)}{r+s} .
$$

The first condition requires the match surplus to be split $\eta / 1-\eta$ between firms and workers on expectation. The match surplus should be split according to the ability of 
each side to create positive versus negative search externalities, depending on the meeting function. When the elasticity of the matching function $\eta$ is high, firms are more efficient than workers in the search process and consequently deserve higher gains from matching. The congestion externality (negative) they impose on the other firms, which want to fill their vacancy too, is lower and the thick-market (positive) externality on job seekers is higher. Symmetrically, when $\eta$ is low, job seekers produce better externalities and so they should receive a higher share of the surplus. The second equation is always satisfied on expectation as it corresponds to the equilibrium job creation condition (13). It is not guaranteed, however, that the profits would cover the vacancy cost once the match is accepted because this cost is already sunk. For instance, a match may generate a positive ex-post surplus (and so is accepted) but may still have a negative ex-ante surplus.

As a corollary of Proposition 1, a decentralized equilibrium can achieve an allocation if and only if the slope of the wage curve, $\frac{\partial w(x)}{\partial y(x)}$, is constant and equal to one. Any efficient allocation $\left(\psi^{*}, \theta^{*}, \xi^{*}\right)$ can be achieved if the wage profile satisfies $w(x)=y(x)-\kappa$, with $\kappa=(r+s) \frac{k}{q\left(\theta^{*}\right)}>0$.

\subsection{Wage setting with taxation}

Once a potential employee and an employer meet, wages are Nash-bargained with a constant bargaining power of workers $\beta$ with $0 \leq \beta<1$. Although this wage setting is standard in the search and matching literature, it plays a crucial role in the model as it results in inefficient equilibria. ${ }^{9}$ The ex-post match surplus defined by a distance $x$ is $\Omega(x)=J(x)+W(x)-U$. Wages are solutions of the following maximization:

$$
\max _{w(x)}(W(x)-U)^{\beta} J(x)^{1-\beta} \text { s.t. (7), (11) and (12). }
$$

The outside options of workers $U$ is taken as fixed because it is not impacted by the individual agreement between the employer and the employee. The wage setting also has indirect consequences on the firm's profit since the tax authority clears its budget constraint. Thus, the value of a job $J(x)$ depends on the average wage $\bar{w}(\xi)$. The firm and the employee do not internalize the effect of the wage setting on the lump-sum component of taxation. This is a reasonable assumption in a model in which the firm's size is negligible compared to the labor market's size and collusion is excluded. Profits are decreasing with wages and the objective function is concave by assuming $1+\tau_{w}>0$. Otherwise, the firm would benefit from setting the highest wage possible. The first-order condition tells how the surplus is split between the two parties. Workers grab a fixed

\footnotetext{
${ }^{9} \mathrm{~A}$ common alternative to wage bargaining is wage posting as in Moen (1997) or in Menzio and Shi (2010) among others. Firms post wages (or job contracts) and workers search accordingly. Moen (1997) assumes away heterogeneity and the framework of Menzio and Shi (2010) would rely on the firms' ability to propose and commit to different wages for different workers depending on their distance in the skill space.
} 
share $\beta_{w}$ of the surplus,

$$
W(x)-U=\beta_{w} \Omega(x),
$$

and the worker's share of the surplus is defined by

$$
\beta_{w}=\frac{\beta}{1+\tau_{w}-\beta \tau_{w}} .
$$

The match surplus $\Omega(x)$ depends on the wage as long as the labor income tax is nonzero. Agents internalize this effect when they bargain the wage. If the tax rate is positive, an employee has to bargain more aggressively to obtain the same wage without taxation because her employer incurs a higher cost of labor (the before-tax wage). This is equivalent to a decline in the worker's share of the surplus, thus $\beta_{w}$ is decreasing in $\tau_{w} .{ }^{10}$ The level of the tax on production is the same regardless of the wage, hence it does not influence surplus sharing.

Averaging equation (16) provides the same relationship for the expected surplus, $\bar{W}(\xi)-U=\beta_{w} \bar{\Omega}(\xi)$. After substitution, the expected wage can be broken down as a weighted average of the expected productivity and the opportunity cost of matching,

$$
\bar{w}(\xi)=\beta_{w} \bar{y}(\xi)+\left(1-\beta_{w}\right) \psi
$$

Equation (16) also leads to $W(x)-\bar{W}(\xi)=\beta_{w}(\Omega(x)-\bar{\Omega}(\xi))$. The relative wage can be formulated as a linear function of the relative productivity after some algebra,

$$
w(x)-\bar{w}(\xi)=\beta_{s}(y(x)-\bar{y}(\xi))
$$

where the slope of the wage curve is defined by

$$
\beta_{s}=\frac{\beta\left(1-\tau_{y}\right)}{1+\tau_{w}}
$$

A steep wage curve deepens the gap between the high-productive and the low-productive jobs. The more progressive is the taxation (i.e. the higher $\tau_{y}$ and $\tau_{w}$ ), the flatter is the wage curve. In absence of taxation, the bargaining power $\beta$ plays several roles. One relates to the worker's share of the surplus $\beta_{w}$, while the other concerns the slope of the wage as a function of productivity $\beta_{s}$. Taxation can decentralize the optimal allocation because it can disentangle these two roles.

By incorporating the surplus-sharing rule in the no-arbitrage condition for free entry (13), equilibrium market tightness can be obtained as a function of the search strategy

\footnotetext{
${ }^{10}$ This is emphasized in Pissarides (1985, 1998); Boone and Bovenberg (2002); Lockwood and Manning (1993).
} 
and the value of an unemployed worker,

$$
\frac{k}{q(\theta)}=\left(1-\beta_{w}\right)\left(\frac{\bar{y}(\xi)-\psi}{r+s}\right)
$$

Market tightness defined here results from the job creation decision of firms given that each job seeker follows the strategy $\xi$ and the value of unemployment is $\psi$. Firms decide to open new vacancies until the total expected vacancy cost equals their share of the total match surplus. The higher their share $\left(1-\beta_{w}\right)$, the higher will be the number of job vacancies per unemployed. The wage is fully determined by equations (18) and (19). The equilibrium search efforts derive from substituting the wage in the optimal search equation (13),

$$
\left\{\begin{array}{ll}
\xi(x)=0 & \text { if } \frac{\beta_{s} y(x)+\left(1-\beta_{s}\right) \bar{y}(\xi)-\psi}{r+s} \leq \frac{k}{q(\theta)} \\
S^{\prime}(\xi(x)) m(\theta)\left(\frac{\beta_{s} y(x)+\left(1-\beta_{s}\right) \bar{y}(\xi)-\psi}{r+s}-\frac{k}{q(\theta)}\right)=1 & \text { else }
\end{array} .\right.
$$

Any search effort function $\xi$ satisfying (20) is an optimal search strategy given market tightness $\theta$ and the value of unemployment $\psi$. There are in general several best strategies. $^{11}$

Definition 2 A decentralized equilibrium is characterized by a value of unemployment $\psi$, market tightness $\theta$ and a search strategy $\xi$ such that equations (2), (19) and (20) are fulfilled, given the tax parameters $\tau_{y}$ and $\tau_{w}$.

In the appendix, a non-degenerated equilibrium is shown to exist if the tax parameters are constrained to $0 \leq \beta_{w}<1$ and $0<\beta_{s} \leq 1$. Given $\tau_{w}>-1$, the set of tax rates for which an equilibrium exists is

$$
\mathcal{T}=\left\{\begin{array}{l|l}
\left(\tau_{w}, \tau_{y}\right) \in \mathbb{R}^{2} & \begin{array}{l}
-1<\tau_{w}<1 \\
1-\frac{1+\tau_{w}}{\beta} \leq \tau_{y}<1
\end{array}
\end{array}\right\}
$$

As the efficient allocations, there are several equilibria in general. The search effort $\xi(x)$ is continuous and decreasing in the distance $x$. Job seekers exert more search efforts for high-productive jobs.

\section{Efficiency and the role of taxation}

This section analyzes the divergence between optimal search behaviors and equilibrium ones, supported by graphical illustrations. The optimal taxation scheme is then characterized and discussed.

\footnotetext{
${ }^{11} \mathrm{~A}$ worker and a firm simultaneously agree on matching if the surplus is positive from (16). One can check that $\frac{\beta_{s} y(x)+\left(1-\beta_{s}\right) \bar{y}(\xi)}{r+s}-\psi-\frac{k}{q(\theta)}>0$ implies $\pi(x)>0$.
} 


\subsection{Two sources of inefficiency}

Comparing equilibrium values to efficient ones is not straightforward. Such an exercise is fortunately meaningless because uniqueness is not guaranteed (for both the decentralized equilibrium and the social optimum). The equilibrium conditions corresponding to the private agents' decisions are compared to the social planner's choices. Parameters $\beta_{w}$ and $\beta_{s}$ impact the equilibrium through two different channels. Each corresponds to a particular source of inefficiency.

Lemma 2 Compared to the social planner decisions,

1. firms do not create enough jobs if and only if $1-\beta_{w} \leq \eta$, when the search strategy and the value of unemployment are given;

2. workers are not selective enough leading to less productive jobs on average if and only if $\beta_{s} \leq 1$, when market tightness and the value of unemployment are given.

This lemma derives from the comparison between equations (4) and (19), and between equations (5) and (20). The proof of the second property, which is not straightforward, is in appendix $\mathrm{C}$.

Suppose the search strategy, $\xi$, and the value of unemployment, $\psi$, to be predetermined. The first point of Lemma 2 states that the best response of firms leads to too slack (respectively too tight) a labor market when the firms' share of the surplus, $1-\beta_{w}$, is below (above) the threshold $\eta$. Failure of the Hosios-Pissarides condition, $\beta_{w}=1-\eta$, leads to a suboptimal quantity of jobs created. ${ }^{12}$ Figure 1 illustrates the optimal surplus sharing in a $(\theta, \bar{w}(\xi))$ plane. Optimal market tightness maximizes the value of unemployment in (2). This condition is equivalent to maximize the utility of the unemployed workers (8) when constrained by the zero-profit condition (13). The zero-profit condition is a fixed decreasing curve in the $(\theta, \bar{w}(\xi))$ plane. The right-hand side of (8) defines a set of decreasing isoutility curves that do not cross each other. Note the isoutility curves have the same horizontal asymptote at level $\psi$. The graphical transcription of the constrained maximization consists in finding the isoutility curve that i) corresponds to the highest workers' utility and, ii) still crosses the zero-profit condition. The isoutility curve is therefore tangent to the zero-profit curve at optimal market tightness. This condition is met only if the surplus is shared according to the weights $\eta$ and $1-\eta$. If the worker's share of the surplus is too low for instance, $\beta_{w}<1-\eta$, then surplus sharing will be inefficient as illustrated on figure 2. The workers' utility can be increased by bargaining a higher equilibrium wage and by reducing market tightness, keeping profits unchanged. ${ }^{13}$

The first inefficiency, requiring the Hosios-Pissarides condition, is widely commented in the literature. It occurs in the standard Diamond-Mortensen-Pissarides framework with homogeneous agents and jobs. The second inefficiency, discussed now, is the cause of inefficient mismatch. Take market tightness and the value of unemployment as fixed. As

\footnotetext{
${ }^{12}$ See Hosios (1990) and Pissarides (2000).

${ }^{13}$ Moen (1997) draws similar graphs with his competitive search framework.
} 


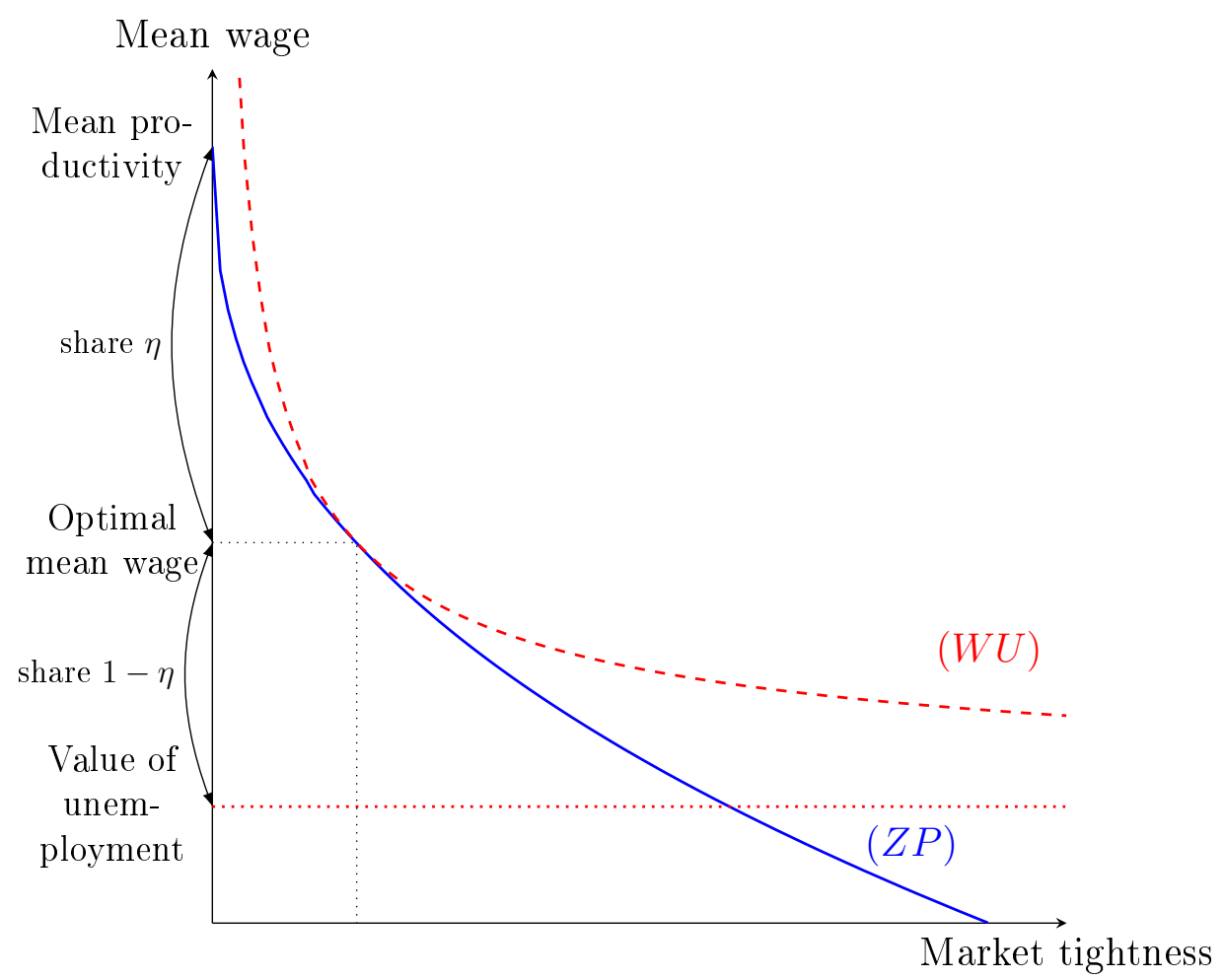

Figure 1: Optimal surplus sharing



Figure 2: Inefficient surplus sharing, with $\beta_{w}<1-\eta$

Note: the $\mathrm{X}$-axis represents market tightness $\theta$ and the $\mathrm{Y}$-axis the mean wage $\bar{w}(\xi)$. The value of unemployment $\psi$ and the search strategy $\xi$ are fixed. The blue curves $(Z P)$ correspond to the zeroprofit condition for firms (13). The red dashed curves are isoutility curves on which a worker's utility, defined by the right-hand side of (8), is a constant. For any isoutility curve, the corresponding value of unemployment is also the level of the horizontal asymptote. 
long as $\beta_{s}<1$, workers make too much efforts in searching for low-productive jobs to the detriment of high-productive jobs for any equilibrium search strategy. As a consequence, the (average) quality of jobs created is too low. This result relies on two main hypotheses: first, the zero-profit condition must hold on each segment of the labor market; second, the search strategy must have an impact on the quality of jobs. The Nash bargain prevents workers from accruing the full benefits of an increase in productivity. Imagine a worker can get a job of productivity $y$ instead of a job of productivity $y^{\prime}$. The output gain, which is also the gain accounted by the social planner, is $y-y^{\prime}$. The worker, however, gains $w(y)-w\left(y^{\prime}\right)=\beta_{s}\left(y-y^{\prime}\right)<y-y^{\prime}$. In the decision to search for a productive job, a worker and the social planner evaluate the cost identically but the gain differently. Consequently, they do not make the same decision: the worker undervalues job quality. The equilibrium search strategy is eventually inefficient in the laissez-faire scenario. The cost of being selective, as an explicit search cost or as an opportunity cost to leave unemployment quicker, is fully incurred by workers or the social planner. Regarding the gains, workers are forced to share the benefits of their strategy with the firms through wage bargaining. Figure 3 depicts the second property of Lemma 2 in an example. The social planner and workers evaluate the gains from searching differently. The two curves $(O W)$ and $(E W)$ represent the gains evaluated respectively by the social planner (optimum) and by workers (decentralized equilibrium). Given the search technology, the two different gain curves lead to two different search strategies, $(O S)$ and $(E S)$. Some low-productive jobs are prospected at equilibrium but should not be so. These jobs produce a positive ex-post surplus: the after-tax output is higher than the value of unemployment. Both the worker and the firm benefit from matching and can bargain a wage. These jobs still have a negative ex-ante surplus: the after-tax output is not high enough to compensate both the value of unemployment and the vacancy cost. Workers, knowingly, apply to these jobs. Even if firms have interest in rejecting such low-quality matches ex-ante, they lack a commitment device to make rejection a credible threat. The vacancy cost, nonetheless, is compensated in expectation (before any meeting) through the entry decision of firms. This is suboptimal according to the second condition in Proposition 1, stating that the ex-ante surplus should be nil for any match. The only exception is when the slope of the wage curve, $\beta_{s}$, is set to 1 . The vacancy cost can be compensated for each match in this particular case. This is done graphically by superimposing the curves $(E W)$ and $(O W)$, leading to a superimposition of the curves $(E S)$ and $(O S)$ by construction. Whatever the production function and the search function (the black curves) are specified, the qualitative result remains: the optimal search strategy is always steeper than the equilibrium search strategy.

From Lemma 2, setting the tax parameters to fulfill $\beta_{w}=1-\eta$ and $\beta_{s}=1$ is a sufficient condition for any equilibrium to be efficient. The next proposition states it as a necessary condition. In other words, the two inefficiencies cannot compensate each other in the laissez-faire economy.

Proposition $2 A$ decentralized equilibrium is efficient if and only if $\beta_{w}=1-\eta$ and 




Search effort

Figure 3: Inefficient vs. efficient search strategy

Note: market tightness $\theta$ and the value of unemployment $\psi$ are fixed. The curve on the north-east part is the production function $y$. The dashed red curve $(E G)$ corresponds to the mapping of any productivity level $y_{0}$ to the gain evaluated by private agents. It is defined in (20), precisely $y_{0} \mapsto$ $\frac{\beta_{s} y_{0}+\left(1-\beta_{s}\right) \bar{y}(\xi)-\psi}{r+s}-\frac{k}{q(\theta)}$. The blue curve $(O G)$, for optimal evaluation of gains, is defined from (5) as $y_{0} \mapsto \frac{y_{0}-\psi}{r+s}-\frac{k}{q(\theta)}$ are represented by the curve $(O G)$. On the south-west part of the graph, the black curve corresponds to the policy function linking gains to the exerted search efforts. This function is the same for the planner and private agents in equations (5) and (20). Lastly, $(E S)$ and $(O S)$ are the graphical representations of the equilibrium and optimal search strategies.

Comment: the graph reads from the north-east part in the counterclockwise direction. Moving $\beta_{s}$ makes the $(E W)$ curve rotate around the intersection point with curve $(O W)$. 
$\beta_{s}=1$.

In particular, the laissez-faire equilibrium is inefficient.

Proof. Suppose there exists $\beta_{w}$ and $\beta_{s}$ such that a decentralized equilibrium $(\psi, \theta, \xi)$ is socially optimal. Therefore, $(\psi, \theta, \xi)$ satisfies simultaneously (2), (4), (5), (19) and (20). Fulfilling simultaneously (4) and (19) imposes $\beta_{w}=1-\eta$. Fulfilling simultaneously (5) and (20) imposes $\beta_{s}=1$.

In absence of taxes, the decentralized equilibrium cannot reconcile the two conditions for optimality. First, the bargaining power should be equal to $1-\eta$ for the entry decision of firms to be optimal. Second, workers should have full bargaining power in order to search efficiently. This second condition makes this externality close to the holdup problem, as formulated by Grout (1984). In holdup problems, workers (or firms) make an investment before matching on the labor market. As the cost of this investment is sunk before any meeting, workers (firms) under-invest for as long as they do not have full bargaining power. Search strategies can thus be compared to worker investments. The difference between the composition externality in this paper and the holdup problem, however, is that the former arises only with endogenous job creation. If the stock of vacancies were fixed instead, the composition externality would disappear. ${ }^{14}$

This result is robust to any specification of the search technology. In the paper, the optimal search strategies are explicitly formulated through a first-order condition thanks to differentiability and convexity assumptions. These assumptions are made for convenience but are not necessary for the result. As long as job seekers can be choosy, meaning they still have the possibility of not visiting some segments of the labor market at no cost, the Proposition holds. The search technology may even be non-continuous. Indeed, the social planner's problem is identical to the workers' under optimal fiscal rules. The optimal policy not only decentralizes the solution of the planner's problem but the problem itself.

\subsection{Optimal taxation}

Optimal tax rates $\tau_{w}$ and $\tau_{y}$ are recovered from Proposition 2.

Proposition 3 A decentralized equilibrium with taxation is efficient if and only if the tax parameters satisfy

$$
\begin{aligned}
\tau_{w}^{*} & =-\frac{1-\beta-\eta}{(1-\beta)(1-\eta)}, \\
\tau_{y}^{*} & =\frac{1-\beta-\eta}{(1-\beta)(1-\eta)}-\frac{\eta}{1-\eta} .
\end{aligned}
$$

\footnotetext{
${ }^{14}$ See Acemoglu (1996, 2001); Acemoglu and Shimer (1999); Davis (2001); Masters (1998) for holdup problems in frictional labor markets.
} 
The lump-sum component of the taxation is always negative,

$$
\tau_{y}^{*} \bar{y}(\xi)+\tau_{w}^{*} \bar{w}(\xi)<0
$$

The fiscal authority debits the following amount for an x-type job:

$$
\tau_{y}^{*} y(x)+\tau_{w}^{*} w(x)-\tau_{y}^{*} \bar{y}(\xi)-\tau_{w}^{*} \bar{w}(\xi)=-\frac{\eta}{1-\eta}(y(x)-\bar{y}(\xi)) .
$$

The optimal tax scheme is anti-redistributive, meaning low-productive jobs are taxed and high-productive jobs are subsidized.

The wage tax is the only policy tool that affects surplus sharing. The optimal rate $\tau_{w}^{*}$ corrects for any gap between the bargaining power of firms $1-\beta$ and the elasticity of the matching function $\eta$. If this gap is negative, $1-\beta<\eta$, the optimal tax rate will be positive to improve the firms' share of the surplus $1-\beta_{w}$ and to adjust it to $\eta$. Boone and Bovenberg (2002) find the same tax rate on wages to restore the Hosios-Pissarides condition. The wage tax modifies the slope of the wage curve but is fixed by the previous condition. The tax on production is the only instrument left to adjust the slope to 1 . The optimal tax parameters may be negative or positive, depending on the value of the bargaining power $\beta$ and the elasticity of the matching function $\eta$. They can never both be simultaneously positive. Increasing the slope of the wage curve requires redistribution from low-productive jobs to high-productive ones. Using optimal tax rates and the wage in (17), the lump-sum component writes as a negative term,

$$
\tau_{y}^{*} \bar{y}(\xi)+\tau_{w}^{*} \bar{w}(\xi)=-\frac{\eta}{(1-\beta)(1-\eta)}[\eta(\bar{y}(\xi)-\psi)+(1-\beta) \psi]<0
$$

The more productive a job is, the more it is subsidized. This idea is close to other results in the literature. Cahuc and Laroque (2014) study the case of monopsony on the labor market with heterogeneous workers. The optimal taxation requires jobs to be subsidized as the firm pays higher wages. Holmstrom (1982) focuses on the moral hazard problem of a principal with multiple agents. To avoid free-riding, the manager pays a bonus when the output is above a certain threshold. The manager is the equivalent to the planner in the present paper.

The optimal taxation formula and its robustness strongly rely on the symmetric comparative advantages assumption. With a more complex heterogeneity, the social planner would give incentives for high-type workers to search more and for low-type workers to search less as Shimer and Smith (2001) suggest. A linear taxation on wages and production may be insufficient, even if the government is able to observe the workers' types.

Corollary 1 When the bargaining power satisfies the Hosios-Pissarides condition, $\beta=$ 


$$
\begin{aligned}
\tau_{w}^{*} & =0, \\
\tau_{y}^{*} & =-\frac{\eta}{1-\eta} .
\end{aligned}
$$

When the Hosios-Pissarides condition is met, the wage tax must be nil to keep an efficient level of jobs created. The marginal taxes can be high in absolute value. For example if $\beta=1-\eta=0.5$, then $\tau_{y}^{*}=-100 \%$. In this case, each job receives the (possibly negative) subsidy $y(x)-\bar{y}(\xi)$. The gain from having a better match is doubled as the surplus difference between two matches of types $x$ and $x^{\prime}$ is $\Omega(x)-\Omega\left(x^{\prime}\right)=2 \frac{y(x)-y\left(x^{\prime}\right)}{r+s}$. Since the surplus sharing is $50-50\left(\beta_{w}=0.5\right)$, the difference $w(x)-w\left(x^{\prime}\right)$ is exactly equal to $y(x)-y\left(x^{\prime}\right)$ as desired. A very similar result in a different setting is obtained by Lockwood (1986).

\section{Other policy instruments}

The combination of a linear tax on production and a linear wage tax is especially relevant since a policy maker only requires to know the elasticity of the matching function and the bargaining power. The solution depends neither on the production function nor the search technology. This section studies the efficiency of other public policies: a minimum wage, a subsidy to job creation, unemployment benefits and a non-linear income taxation. Any of these can replace the tax on production in restoring the social optimum.

\subsection{Minimum wage}

In an equilibrium without taxes $\left(\tau_{w}=\tau_{y}=0\right)$, a minimum wage $\underline{w}$ is equivalent to banning jobs that are not productive enough, namely when productivity $y(x)$ is below $\underline{w}$. The government can then prevent the worker from applying for jobs whose ex-ante surplus is negative. The wage bargaining for the remaining jobs, however, remains unchanged. Workers still exert an insufficient search effort for high-productive jobs. In the lens of the model, a minimum wage can only decentralize the first part of the optimal condition in equation (5). This result is sufficient in the special case where search is only an extensive margin (a binary decision for each market) as in the model of Decreuse (2008). Otherwise, the composition externality cannot be corrected in the general case.

\subsection{Subsidizing job creation}

In addition to the tax on production and the wage tax, assume the government provides a financial aid $A$ for each vacancy opened, which is financed by a lump-sum tax $\tau_{l}$ on jobs. The free entry of firms implies equality between the expected cost of a vacancy and the 
expected profit at equilibrium,

$$
\frac{k}{q(\theta)}-A=\frac{\bar{y}(\xi)-\bar{w}(\xi)-\tau_{l}}{r+s} .
$$

The budget constraint is cleared when the present-discounted tax revenue from the newly created jobs $\frac{\tau_{l}}{r+s} \times S^{T}(\xi) m(\theta) u$ is equal to the financial support provided to the newly opened vacancies $A \times q(\theta) v$. Consequently, equation (13') is identical to (13) once we account for the budget clearing condition, $A=\frac{\tau_{l}}{r+s}$. This policy consists in redistribution from the firms with a filled vacancy towards the firms with an open vacancy. Yet, the firms' entry decision is modified as the lump-sum tax is shared with the employed workers through the Nash bargain,

$$
\bar{w}(\xi)=\beta_{w}(\bar{y}(\xi)-(r+s) A)+\left(1-\beta_{w}\right) \psi
$$

Workers contribute to the subsidy for opening vacancies. The wage equation (18) is unchanged since the lump-sum tax does not by definition vary with production. The equilibrium equation (19) with endogenous wage becomes

$$
\frac{k}{q(\theta)}=\left(1-\beta_{w}\right)\left(\frac{\bar{y}(\xi)-\psi}{r+s}\right)+\beta_{w} A .
$$

The value of unemployment defined by equation (2) remains the same, as well as the search strategy of job seekers in (20). The equilibrium is defined by equations (2), (19') and (20). A subsidy for job creation financed by a lump-sum tax can restore efficient job creation. The subsidy $A$ must be such that the left-hand side of (19') coincides with the left-hand side of (4). In particular, jobs will be taxed and the subsidy will be positive when the firms' share of the surplus $\left(1-\beta_{w}\right)$ is below its efficient value $\eta$, and vice versa. This requires the fiscal authority to know the equilibrium values of the average productivity $\bar{y}(\xi)$ and the value of unemployment $\psi$, which depends on the deep parameters of the model. The subsidy to job creation, however, does not intervene in the search effort decisions. The composition externality cannot be tackled without the tax on production.

\subsection{Unemployment benefits}

Now, the fiscal authority provides unemployment benefits $b$ to unemployed workers instead of a subsidy to job creation, still financed by a lump-sum tax $\tau_{l}$. Unemployment benefits boost the return to unemployment,

$$
r U=b-\xi^{T}+S^{T}(\xi) m(\theta)(\bar{W}(\xi)-U)
$$

The no-arbitrage condition from the free entry of firms can be written

$$
\frac{k}{q(\theta)}=\frac{\bar{y}(\xi)-\bar{w}(\xi)-\tau_{l}}{r+s} .
$$


The present-discounted tax revenues from the new matches are $\frac{\tau_{l}}{r+s} S^{T}(\xi) m(\theta) u$. The budget is balanced if this term exactly compensates the spendings for unemployment benefits $b u$. The lump-sum tax is shared between the employers and the employees. The expected wage then follows

$$
\bar{w}(\xi)=\beta_{w}\left(\bar{y}(\xi)-\frac{(r+s) b}{S^{T}(\xi) m(\theta)}\right)+\left(1-\beta_{w}\right) \psi
$$

This policy is equivalent to redistribution from employed workers to unemployed workers. The lump-sum tax induces firms to open less vacancies given the search strategy of workers according to the following equilibrium condition, analogous to (19),

$$
\frac{k}{q(\theta)}=\left(1-\beta_{w}\right)\left(\frac{\bar{y}(\xi)-\psi}{r+s}-\frac{b}{S^{T}(\xi) m(\theta)}\right)
$$

In the previous case with a subsidy for jobs, workers are compensated for the tax burden by a higher job-finding rate. They do not have this compensation mechanism when the tax finances unemployment benefits, so equation (19") differs from (19).

The equilibrium equation associated with the search strategy is

$$
\left\{\begin{array}{lr}
\xi(x)=0 \quad & \text { if } \frac{\beta_{s} y(x)+\left(1-\beta_{s}\right) \bar{y}(\xi)-\psi}{r+s}-\frac{b}{S^{T}(\xi) m(\theta)}-\frac{k}{q(\theta)} \leq 0 \\
S^{\prime}(\xi(x)) m(\theta)\left(\frac{\beta_{s} y(x)+\left(1-\beta_{s}\right) \bar{y}(\xi)-\psi}{r+s}-\frac{b}{S^{T}(\xi) m(\theta)}-\frac{k}{q(\theta)}\right)=1 \quad \text { else }
\end{array} .\right.
$$

The marginal benefit from searching is reduced for each job because of the tax, therefore search efforts are reduced.

Unemployment benefits financed by a lump-sum tax on jobs alter both channels of inefficiency. As with a subsidy for job creation, an efficient level of job creation can be achieved. Nevertheless, the sole use of unemployment benefits as tax instruments cannot alleviate the second inefficiency. Search efforts should increase for high-type jobs and decrease for low-type jobs whereas a change in unemployment benefits makes all search efforts jointly increase or decrease.

\subsection{Non-linear income taxation}

Assume the government taxes production at a constant rate $\tau_{y}$ and can raise a tax $T(w)$ from each job providing an after-tax wage $w$. Income taxation is no longer imposed to be linear. The government gives a lump-sum payment $\tau_{y} \bar{y}(\xi)$ to self-finance the tax on production. The flow profit writes $\pi(x)=y(x)-w(x)-T[w(x)]-\tau_{y}[y(x)-\bar{y}(\xi)]$. The new wage bargain involves the derivative of the tax function $T^{\prime}$,

$$
w(x)=\frac{\beta\left(y(x)-T[w(x)]-\tau_{y}[y(x)-\bar{y}(\xi)]\right)}{1+(1-\beta) T^{\prime}[w(x)]}+\frac{(1-\beta)\left(1+T^{\prime}[w(x)]\right)}{1+(1-\beta) T^{\prime}[w(x)]} \psi .
$$


The problem of optimal taxation consists in finding $T$ and $\tau_{y}$ such that:

$$
\begin{aligned}
& w(x)=y(x)-\eta(\bar{y}(\xi)-\psi) \\
& 2 \int_{0}^{\frac{1}{2}} T(w(x)) \frac{S(\xi(x))}{S^{T}(\xi)} d x=0
\end{aligned}
$$

The first equation is the definition of the efficient wage profile in Proposition 1 . The government's budget constraint is balanced when total tax receipts are nil; this is the second condition. Suppose $T$ makes $(24)$ is true. One can substitute $y(x)$ in equation (23). The optimal wage tax must be a solution of the following differential equation:

$$
T^{\prime}(w)+\frac{\beta}{(1-\beta)(w-\psi)} T(w)=\beta \frac{\left[\eta+\tau_{y}-\eta \tau_{y}\right](\bar{y}(\xi)-\psi)}{(1-\beta)(w-\psi)}+\frac{-1+\beta-\beta \tau_{y}}{1-\beta} .
$$

$T$ should be of the form

$$
T(w)=\left[\eta+\tau_{y}-\eta \tau_{y}\right](\bar{y}(\xi)-\psi)+\left[-1+\beta-\beta \tau_{y}\right](w-\psi)-c(w-\psi)^{-\frac{\beta}{1-\beta}}
$$

with $c$ a free parameter. Since the taxation function is bounded, $c$ is necessarily equal to $0 .{ }^{15}$ Labor income taxation is linear and one obtains the values from Proposition 3 using condition (25). A tax on production is thus required in addition to the wage tax.

\section{Calibration}

A calibration of the model provides quantitative measures of the welfare loss and the magnitude of optimal taxation. The time scale is normalized so that one period is a month. The discount rate is chosen to match an annual interest rate of $4.5 \%$. The job destruction rate is such that $10 \%$ of jobs break each quarter, which is the estimate of Shimer (2005). Productivity and the vacancy cost are normalized for the most productive match to produce $y_{0}=100$ per time unit. Equivalently, we can interpret productivity as a percentage of the most productive job. The production function belongs to the family of functions $x \mapsto\left(y_{0}-y_{1 / 2}\right)(1-2 x)^{e_{y}}+y_{1 / 2}$, with parameters $y_{0}$ and $y_{1 / 2}$ defining the extreme values of productivity, and $e_{y}$ measuring concavity. The quantitative results strongly depend on this specification. There is no obvious empirical counterpart of this function. For a parsimonious calibration, the worst feasible match is arbitrarily assumed half-productive, $y_{1 / 2}=50$. For each job, half of the workers are considered as being able to produce at least $80 \%$ of the best match for each job, $y(0.25)=80$. This requires $e_{y}=0.74$ and the production function to be concave. ${ }^{16}$ Holding an open vacancy costs $20 \%$ of the production of the best match, $k=20$, close to the parameter chosen by Shimer

\footnotetext{
${ }^{15}$ When $c \neq 0$, the absolute value of $T(\psi)$ tends to infinity and so do profits. The bargaining strategy of firms would be degenerated.

${ }^{16}$ In a simpler version of the model where search is an extensive margin, concavity of the production function guarantees equilibrium uniqueness according to Decreuse (2008). Uniqueness is not proved here, but the calibrated model is unique according to a numerical analysis.
} 
(2005).

The second crucial parameter is the search technology. Multiplying the matching function $m($.$) is equivalent to multiplying the search function S($.$) by the same coefficient.$ The matching function is normalized so that $m(1)=1$, which implies $m(\theta)=\theta^{\eta}$. The search function is taken in the family of isoelastic functions, $S(z)=S_{1} z^{e_{s}}$, with $S_{1}$ and $e_{s}$ the two parameters. An isoelastic search function provides a simpler interpretation of the optimal search decisions. By comparing the optimal search effort for jobs at a distance $x_{1}$ and $x_{2}$ in the skill space, it follows that

$$
\frac{S\left(\xi\left(x_{1}\right)\right)}{S\left(\xi\left(x_{2}\right)\right)}=\left(\frac{\xi\left(x_{1}\right)}{\xi\left(x_{2}\right)}\right)^{e_{s}}=\left(\frac{W\left(x_{1}\right)-U}{W\left(x_{2}\right)-U}\right)^{\frac{e_{s}}{1-e_{s}}}
$$

when the search efforts $\xi\left(x_{1}\right)$ and $\xi\left(x_{2}\right)$ are non-zero. If the relative gain from matching with a firm at distance $x_{1}$ compared to distance $x_{2}, \frac{W\left(x_{1}\right)-U}{W\left(x_{2}\right)-U}$, increases by $1 \%$, then the relative search intensity, $\frac{S\left(\xi\left(x_{1}\right)\right)}{S\left(\xi\left(x_{2}\right)\right)}$, increases by $\frac{e_{s}}{1-e_{s}} \%$. There is no benchmark for parameters $S_{1}$ and $e_{s}$. They are chosen to match the equilibrium unemployment rate at $6 \%$ and the total search cost at $25 \%$ of the highest productivity level in the baseline case $\beta=1-\eta=0.5$, which will be our benchmark. The values are accordingly $S_{1}=0.1$ and $e_{s}=0.25$. Table 1 sums up the values chosen for the parameters.

\begin{tabular}{|c|c|c|}
\hline Parameter & Target/Motive & Value \\
\hline Discount rate, $r$ & Annual interest rate of $4.5 \%$ & 0.0037 \\
\hline $\begin{array}{l}\text { Exogenous job destruction } \\
\text { rate, } s\end{array}$ & $10 \%$ of jobs break each quarter & 0.035 \\
\hline Production function, $y(x)$ & $\begin{array}{l}\text { The best match produces } 100 \text {. } \\
\text { The worst feasible match pro- } \\
\text { duces } 50 \text {. Half of the workers can } \\
\text { produce at least } 80 \text {. }\end{array}$ & $50(1-2 x)^{0.74}+50$ \\
\hline Vacancy cost, $k$ & $20 \%$ of the best match & 20 \\
\hline Matching function $m(\theta)$ & $\begin{array}{l}\text { Multiplicative factor normalized } \\
\text { to } 1\end{array}$ & $\theta^{\eta}$ \\
\hline Search function $S(z)$ & $\begin{array}{l}\text { Unemployment rate at } 6 \% \text { and } \\
\text { search costs at } 25 \text { in the bench- } \\
\text { mark model }\end{array}$ & $S(z)=0.1 z^{0.25}$ \\
\hline
\end{tabular}

Table 1: Parameters for the calibration

Note: The time unit is a month.

With these parameters, the equilibrium for different values of the elasticity of the matching function $\eta$ and the bargaining power $\beta$ is computed. The optimum values and optimal taxes are provided to compare with the equilibrium in the laissez-faire case. Results are given in table 2. Remember that the social planner maximizes the value of unemployment, $\psi$. Comparing the welfare is equivalent to comparing $\psi$ in the case with and without optimal taxes. In the laissez-faire scenario, the welfare loss lies between $0.1 \%$ and $19 \%$. Focusing on the case when the bargaining power is 0.5 , the loss ranges from $1.4 \%$ to $7 \%$. As workers are not selective enough, the average productivity is always 


\begin{tabular}{|c|c|c|c|c|c|c|c|c|}
\hline \multirow{2}{*}{$\begin{array}{c}\text { Elasticity } \\
\eta\end{array}$} & \multirow{2}{*}{$\begin{array}{c}\text { Bargaining } \\
\beta\end{array}$} & \multicolumn{2}{|c|}{ Job quality } & \multicolumn{2}{|c|}{ Unemployment } & \multicolumn{2}{|c|}{ Welfare } & \multirow{2}{*}{$\begin{array}{l}\text { Welf. loss } \\
\frac{\psi^{o}-\psi^{e}}{\psi^{o}}\end{array}$} \\
\hline & & $\bar{y}^{e}$ & $\bar{y}^{o}$ & $u^{e}$ & $u^{o}$ & $\psi^{e}$ & $\psi^{o}$ & \\
\hline 0.25 & 0.25 & 87.5 & 92.2 & $4.3 \%$ & $8.7 \%$ & 69.2 & 77.7 & $11 \%$ \\
\hline 0.25 & 0.5 & 90 & 92.2 & $6 \%$ & $8.7 \%$ & 75.7 & 77.7 & $2.5 \%$ \\
\hline 0.25 & 0.75 & 90.7 & 92.2 & $8 \%$ & $8.7 \%$ & 77.5 & 77.7 & $0.2 \%$ \\
\hline 0.5 & 0.25 & 88.9 & 93.7 & $3.6 \%$ & $7.2 \%$ & 72.8 & 76.4 & $4.7 \%$ \\
\hline 0.5 & 0.5 & 89.8 & 93.7 & $6.2 \%$ & $7.2 \%$ & 75.3 & 76.4 & $1.4 \%$ \\
\hline 0.5 & 0.75 & 88.9 & 93.7 & $10.1 \%$ & $7.2 \%$ & 72.8 & 76.4 & $4.7 \%$ \\
\hline 0.75 & 0.25 & 90.5 & 96.9 & $2.9 \%$ & $3.4 \%$ & 77.1 & 80.4 & $4 \%$ \\
\hline 0.75 & 0.5 & 89.6 & 96.9 & $6.4 \%$ & $3.4 \%$ & 74.6 & 80.4 & $7.1 \%$ \\
\hline 0.75 & 0.75 & 86 & 96.9 & $14.1 \%$ & $3.4 \%$ & 64.9 & 80.4 & $19.2 \%$ \\
\hline
\end{tabular}
Elasticity Bargaining $\quad$ Optimal Tax

\begin{tabular}{cc||ccc}
$\eta$ & $\beta$ & $\tau_{y}^{*}$ & $\tau_{w}^{*}$ & $T_{0}^{*}$ \\
\hline 0.25 & 0.25 & 0.56 & -0.89 & -27.5 \\
0.25 & 0.5 & 0.33 & -0.67 & -28.3 \\
0.25 & 0.75 & -0.33 & 0 & -30.7 \\
0.5 & 0.25 & -0.33 & -0.67 & -87.9 \\
0.5 & 0.5 & -1 & 0 & -93.7 \\
0.5 & 0.75 & -3 & 2 & -111.1 \\
0.75 & 0.25 & -3 & 0 & -290.8 \\
0.75 & 0.5 & -5 & 2 & -315.7 \\
0.75 & 0.75 & -11 & 8 & -390.4
\end{tabular}

Table 2: Various simulations of the model, for different matching elasticities $\eta$ and bargaining power $\beta$

Note. For each couple $(\eta, \beta)$, we simulate the average productivity of jobs $\bar{y}$, the unemployment rate $u$ and the value of unemployment $\psi$ at the laissez-faire equilibrium and at the optimal level, respectively with the superscripts $e$ and $o$. The optimal tax parameters are $\tau_{y}^{*}$ for the production tax, $\tau_{w}^{*}$ for the wage tax and $T_{0}^{*}$ for the lump-sum component. 
higher in the optimal case by 5 to 12 percentage points of the best match.

Intuitively, we could expect the unemployment rate to be higher at the optimum than at the laissez-faire equilibrium because workers might reduce their job-finding rate as they are more selective. This is not always true. The decision of job seekers is not only an allocation of the total search effort $\xi^{T}$ across segments of the labor market, but also a choice for this search effort. By increasing her search efforts on each segment and searching even more for high-productive jobs, it is possible for a worker to be more selective and to have a higher job-finding rate.

It was previously proved that the optimal tax rates, $\tau_{y}^{*}$ and $\tau_{w}^{*}$, are invariant to a change in any of the parameters of the calibration from table 1 . The optimal tax rates skyrocket in absolute value when the elasticity of the matching function is high. In these situations, firms create good search externalities on the labor market. They should obtain a high share of the surplus, or equivalently workers should have low bargaining power, so that an optimal quantity of jobs is created. On the other hand, fixing a low bargaining power reduces the selectivity of job seekers. Consequently, when the policy maker sets a high wage tax to improve the surplus sharing, it amplifies the composition externality which requires a stronger taxation on production.

\section{Conclusion}

This paper examines the optimal fiscal policy in presence of inefficient job mismatch due to a composition externality. It sheds light on a harmful consequence of redistributive taxation, which has been absent in the literature. The selectivity of job seekers matters for firms as it determines the quality of jobs. Job seekers, however, do not internalize this composition externality and make suboptimal search decisions. Redistribution thus amplifies this inefficiency. To emphasize the main mechanism, the model abstracts from a variety of considerations such as social preferences for equity or (asymmetric) heterogeneity in skills. The paper is not aimed at recommending such an anti-redistributive taxation on the labor market.

In practice, whether the composition externality is large or not depends on two key channels: i) how the job creation decisions are made in function of job productivity; ii) how the mismatch reduces job productivity. The optimal policy, however, does not depend on these parameters.

The composition externality shares similar mechanisms with holdup problems. In particular, the tax scheme suggested here decentralizes the social optimum in a search and matching model with homogeneous agents and workers' investments. This paper also provides a general recipe for holdup in firms' investments, in which the slope of the wage curve should be substituted by the slope of the profits curve in the analysis. 


\section{References}

D. Acemoglu. A Microfoundation for Social Increasing Returns in Human Capital Accumulation. The Quarterly Journal of Economics, 111(3):779-804, August 1996.

D. Acemoglu. Good Jobs versus Bad Jobs. Journal of Labor Economics, 19(1):1-21, January 2001.

D. Acemoglu and R. Shimer. Holdups and Efficiency with Search Frictions. International Economic Review, 40(4):827-849, 1999.

S. Amine and P. L. D. Santos. L'interaction entre les politiques sociales et les choix technologiques des entreprises : le cas de l'impôt n 'egatif. Revue d'économie politique, 118(3):395-409, 2008.

J. Boone and L. Bovenberg. Optimal labour taxation and search. Journal of Public Economics, 85(1):53-97, July 2002.

P. Cahuc and G. Laroque. Optimal Taxation and Monopsonistic Labor Market: Does Monopsony Justify the Minimum Wage? Journal of Public Economic Theory, 16(2): 259-273, 042014.

O. Charlot and B. Decreuse. Self-selection in education with matching frictions. Labour Economics, 12(2):251-267, April 2005.

S. J. Davis. The Quality Distribution of Jobs and the Structure of Wages in Search Equilibrium. NBER Working Papers 8434, National Bureau of Economic Research, Inc, Aug. 2001.

B. Decreuse. Choosy Search and the Mismatch of Talents. International Economic Review, 49(3):1067-1089, August 2008.

P. A. Grout. Investment and Wages in the Absence of Binding Contracts: A Nash Bargaining Approach. Econometrica, 52(2):449-460, March 1984.

B. Holmstrom. Moral Hazard in Teams. Bell Journal of Economics, 13(2):324-340, Autumn 1982.

A. J. Hosios. On the Efficiency of Matching and Related Models of Search and Unemployment. Review of Economic Studies, 57(2):279-298, April 1990.

M. Hungerbühler, E. Lehmann, A. Parmentier, and B. V. D. Linden. Optimal Redistributive Taxation in a Search Equilibrium Model. Review of Economic Studies, 73(3): 743-767, 2006.

B. Lockwood. Transferable Skills, Job Matching, and the Inefficiency of the 'Natural' Rate of Unemployment. Economic Journal, 96(384):961-74, December 1986. 
B. Lockwood and A. Manning. Wage setting and the tax system theory and evidence for the United Kingdom. Journal of Public Economics, 52(1):1-29, August 1993.

R. Marimon and F. Zilibotti. Unemployment vs. Mismatch of Talents: Reconsidering Unemployment Benefits. Economic Journal, 109(455):266-91, April 1999.

A. M. Masters. Efficiency of Investment in Human and Physical Capital in a Model of Bilateral Search and Bargaining. International Economic Review, 39(2):477-94, May 1998.

G. Menzio and S. Shi. Directed Search on the Job, Heterogeneity, and Aggregate Fluctuations. American Economic Review, 100(2):327-32, May 2010.

E. R. Moen. Competitive Search Equilibrium. Journal of Political Economy, 105(2): 385-411, April 1997.

D. T. Mortensen. Property Rights and Efficiency in Mating, Racing, and Related Games. American Economic Review, 72(5):968-79, December 1982.

C. A. Pissarides. Taxes, Subsidies, and Equilibrium Unemployment. Review of Economic Studies, 52(1):121-33, January 1985.

C. A. Pissarides. The impact of employment tax cuts on unemployment and wages; The role of unemployment benefits and tax structure. European Economic Review, 42(1): 155-183, January 1998.

C. A. Pissarides. Equilibrium Unemployment Theory. The MIT press, 2000. Second Edition.

S. C. Salop. Monopolistic Competition with Outside Goods. The Bell Journal of Economics, 10(1):141-156, Spring 1979.

R. Shimer. The Cyclical Behavior of Equilibrium Unemployment and Vacancies. American Economic Review, 95(1):25-49, March 2005.

R. Shimer and L. Smith. Assortative Matching and Search. Econometrica, 28(2):343-369, March 2000.

R. Shimer and L. Smith. Matching, Search, and Heterogeneity. The B.E. Journal of Macroeconomics, 1(1):1-18, April 2001.

L. Uren. The Allocation of Labor and Endogenous Search Decisions. The B.E. Journal of Macroeconomics, 6(1):1-31, June 2006. 


\section{A Lemma 1}

Let $H(\theta, \xi, Y, u, \lambda, \mu)$ be the current-value Hamiltonian of problem (1), with $\lambda$ and $\mu$ the multipliers of the two constraints. Hereafter, we denote it $H$ for ease of reading. It is defined as

$$
H=Y-k S^{T}(\xi) \theta u-\xi^{T} u+\lambda\left[S^{T}(\xi) m(\theta) u \bar{y}(\xi)-s Y\right]+\mu\left[s(1-u)-S^{T}(\xi) m(\theta) u\right] .
$$

The two costate equations at steady state write $\frac{\partial H}{\partial Y}=r \lambda$ and $\frac{\partial H}{\partial u}=r \mu$. The costate equation associated with the output dynamics determines the shadow price of a unit of production, $\lambda$, as

$$
\lambda=\frac{1}{r+s} .
$$

The relative value of unemployment is defined as $\psi=\frac{\mu}{\lambda}=(r+s) \mu$. Equation (2) derives from the second costate equation, after having substituted $\lambda$ by its expression.

The optimal market tightness, $\theta$, and search strategy, $\xi$, maximize the Hamitonian. It is linear with the unemployment rate: $H=H_{0}+\frac{\partial H}{\partial u} u$ where $H_{0}$ does not depend on $\theta$ and $\xi$. The planner's problem is thus equivalent to maximizing $\frac{\partial H}{\partial u}$ i.e. the value of an unemployed worker $\mu$ according to the second costate equation. This is equivalent to problem (3).

\section{B Existence of an equilibrium and an optimal alloca- tion}

We restrict our attention to the case where $0 \leq \beta_{w}<1$ and $0<\beta_{s} \leq 1$. A function $F$ is built such that its fixed points characterize the equilibria of the model. A non-trivial fixed point is then shown to exist. Given an expected average productivity $\tilde{y}$, a value of unemployment $\psi$ and a market tightness $\theta$, workers search according to equation (20). For a distance $x$ in the skill space, they exert an effort

$$
\xi^{*}[\tilde{y}, \psi, \theta](x)=S^{\prime-1}\left(\frac{1}{m(\theta) \max \left\{\frac{\beta_{s} y(x)+\left(1-\beta_{s}\right) \tilde{y}-\psi}{r+s}-\frac{k}{q(\theta)}, 0\right\}}\right) .
$$

This search strategy results in a realized average productivity, a total search intensity and a total search effort given respectively by the following auxiliary functions:

$$
\begin{aligned}
& G_{1}(\tilde{y}, \psi, \theta)=\bar{y}\left(\xi^{*}[\tilde{y}, \psi, \theta]\right)=\frac{\int_{0}^{\frac{1}{2}} S\left(\xi^{*}[\tilde{y}, \psi, \theta](x)\right) y(x) d x}{\int_{0}^{\frac{1}{2}} S\left(\xi^{*}[\tilde{y}, \psi, \theta](x)\right) d x}, \\
& G_{2}(\tilde{y}, \psi, \theta)=S^{T}\left(\xi^{*}[\tilde{y}, \psi, \theta]\right)=2 \int_{0}^{\frac{1}{2}} S\left(\xi^{*}[\tilde{y}, \psi, \theta](x)\right) d x, \\
& G_{3}(\tilde{y}, \psi, \theta)=\xi^{* T}[\tilde{y}, \psi, \theta]=2 \int_{0}^{\frac{1}{2}} \xi^{*}[\tilde{y}, \psi, \theta](x) d x .
\end{aligned}
$$


Let $F$ be a function as

$$
F(\tilde{y}, \psi, \theta)=\left(F_{1}(\tilde{y}, \psi, \theta), F_{2}(\tilde{y}, \psi, \theta), F_{3}(\tilde{y}, \psi, \theta)\right)
$$

and

$$
\begin{aligned}
F_{1}(\tilde{y}, \psi, \theta) & =\beta_{s} G_{1}(\tilde{y}, \psi, \theta)+\left(1-\beta_{s}\right) \tilde{y} \\
F_{2}(\tilde{y}, \psi, \theta) & =\frac{G_{2}(\tilde{y}, \psi, \theta) m(\theta)}{r+s+G_{2}(\tilde{y}, \psi, \theta) m(\theta)}\left(F_{1}(\tilde{y}, \psi, \theta)-\frac{(r+s) k}{q(\theta)}\right) \\
& -\frac{(r+s) G_{3}(\tilde{y}, \psi, \theta)}{r+s+G_{2}(\tilde{y}, \psi, \theta) m(\theta)}, \\
F_{3}(\tilde{y}, \psi, \theta) & =q^{-1}\left(\frac{(r+s) k}{\left(1-\beta_{w}\right)\left(F_{1}(\tilde{y}, \psi, \theta)-F_{2}(\tilde{y}, \psi, \theta)\right)}\right) .
\end{aligned}
$$

Functions $F_{2}$ and $F_{3}$ correspond to the conditions (2) and (19). Any fixed point $\left(\tilde{y}^{*}, \psi^{*}, \theta^{*}\right)$ of $F$ is associated with an equilibrium characterized by a value of unemployment $\psi^{*}$, a market tightness $\theta^{*}$ and a search strategy $\xi^{*}\left[\tilde{y}^{*}, \psi^{*}, \theta^{*}\right]$. Define the set

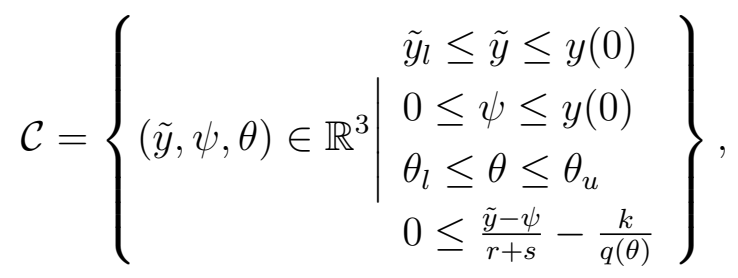

with

$$
\begin{gathered}
\tilde{y}_{l}=2 \int_{0}^{\frac{1}{2}} y(x) d x, \quad \theta_{u}=q^{-1}\left(\frac{k}{\left(1-\beta_{w}\right) \frac{y(0)}{r+s}}\right), \\
\theta_{l}=q^{-1}\left(\frac{k\left(r+s+S \circ S^{\prime-1}\left(\frac{r+s}{m\left(\theta_{u}\right) y(0)}\right) m\left(\theta_{u}\right)\right)}{\left(1-\beta_{w}\right) \tilde{y}_{l}}\right) .
\end{gathered}
$$

$F$ is continuous on $\mathcal{C}$. The constraint $0 \leq \frac{\tilde{y}-\psi}{r+s}-\frac{k}{q(\theta)}$ implies the existence of some $x$ such that $\frac{\beta_{s} y(x)+\left(1-\beta_{s}\right) \tilde{y}-\psi}{r+s}-\frac{k}{q(\theta)}>0 . m(\theta)>0$ since $\theta>0$ in $\mathcal{C}$. As $\lim _{\xi_{0} \rightarrow 0} S^{\prime}\left(\xi_{0}\right)=+\infty$, the search strategy $\xi^{*}[\tilde{y}, \psi, \theta]$ is not degenerated in the sense that $\xi^{*}[\tilde{y}, \psi, \theta](x)>0$ for some $x$. Workers exert a nonzero search effort for some markets. The denominator in $G_{1}$ cannot be nil. Thus, functions $G_{1}, G_{2}$ and $G_{3}$ are well-defined and continuous on $\mathcal{C}$. By elementary operations, one can deduce that $F_{1}$ and $F_{2}$ are continuous. The definition of $F_{2}$ implies

$$
\begin{aligned}
F_{1}(\tilde{y}, \psi, \theta)-F_{2}(\tilde{y}, \psi, \theta) & =\frac{r+s}{r+s+G_{2}(\psi, \theta, \tilde{y}) m(\theta)}\left(F_{1}(\tilde{y}, \psi, \theta)+\frac{(r+s) k}{q(\theta)}\right) \\
& +\frac{(r+s) G_{3}(\psi, \theta, \tilde{y})}{r+s+G_{2}(\psi, \theta, \tilde{y}) m(\theta)} .
\end{aligned}
$$


The denominator of $F_{3}$ is always strictly positive, so $F_{3}$ is also continuous. $F$ is continuous on $\mathcal{C}$.

$\mathcal{C}$ is stable by $F$. Fix $(\tilde{y}, \psi, \theta)$ in $\mathcal{C}$. Let's show that $F(\tilde{y}, \psi, \theta)$ is in $\mathcal{C}$. Define

$$
p(x)=\frac{S\left(\xi^{*}[\tilde{y}, \psi, \theta](x)\right)}{\int_{0}^{\frac{1}{2}} S\left(\xi^{*}[\tilde{y}, \psi, \theta](x)\right) d x} .
$$

$p$ is the probability density function of a distribution on $(0,1 / 2)$. As $p$ is decreasing, the cumulative density function $P$ associated to $p$ is concave on $(0,1 / 2)$, with $P(0)=0$ and $P(1 / 2)=1$. The convexity inequality implies $P(x)>2 x$. The distribution has firstorder stochastic dominance over the uniform probability. It derives from this result that $G_{1}(\tilde{y}, \psi, \theta) \geq \tilde{y}_{l}$ and then $F_{1}(\tilde{y}, \psi, \theta) \geq \tilde{y}_{l} . y(x) \leq y(0)$ implies $F_{1}(\tilde{y}, \psi, \theta) \leq y(0)$.

Straightforwardly, $F_{2}(\tilde{y}, \psi, \theta) \leq F_{1}(\tilde{y}, \psi, \theta) \leq y(0)$. Then define

$$
G_{4}(\tilde{y}, \psi, \theta)=G_{2}(\tilde{y}, \psi, \theta) m(\theta)\left(\frac{F_{1}(\tilde{y}, \psi, \theta)-\psi}{r+s}-\frac{k}{q(\theta)}\right)-G_{3}(\tilde{y}, \psi, \theta)
$$

so that $F_{2}(\tilde{y}, \psi, \theta)=(r+s) \frac{G_{4}(\tilde{y}, \psi, \theta)+G_{2}(\tilde{y}, \psi, \theta) m(\theta) \psi}{r+s+G_{2}(\tilde{y}, \psi, \theta) m(\theta)}$. Notice

$$
G_{4}(\tilde{y}, \psi, \theta)=\max _{\xi}\left\{2 \int_{0}^{\frac{1}{2}}\left[S(\xi(x)) m(\theta)\left(\frac{\beta_{s} y(x)+\left(1-\beta_{s}\right) \tilde{y}-\psi}{r+s}-\frac{k}{q(\theta)}\right)-\xi(x)\right] d x\right\}
$$

$G_{4}(\tilde{y}, \psi, \theta)$ is necessarily positive because the objective function is zero when $\xi$ is the nil function. Therefore, $F_{2}(\tilde{y}, \psi, \theta) \geq 0$.

From the previous results, $F_{1}(\tilde{y}, \psi, \theta)-F_{2}(\tilde{y}, \psi, \theta) \leq y(0)$, which implies $F_{3}(\tilde{y}, \psi, \theta) \leq$ $\theta_{u}$. Equation (28) provides the lower bound

$$
F_{1}(\tilde{y}, \psi, \theta)-F_{2}(\tilde{y}, \psi, \theta) \geq \frac{(r+s) \tilde{y}_{l}}{r+s+G_{2}(\psi, \theta, \tilde{y}) m(\theta)}
$$

In addition, $m(\theta) \leq m\left(\theta_{u}\right)$ and $G_{2}(\psi, \theta, \tilde{y}) \leq S \circ S^{\prime-1}\left(\frac{1}{m\left(\theta_{u}\right) \frac{y(0)}{r+s}}\right)$. It results $F_{3}(\tilde{y}, \psi, \theta) \geq$ $\theta_{l}$.

Lastly, use $F_{1}(\tilde{y}, \psi, \theta) \geq F_{2}(\tilde{y}, \psi, \theta)$ with the definition of $F_{3}$ to deduce

$$
\frac{F_{1}(\tilde{y}, \psi, \theta)-F_{2}(\tilde{y}, \psi, \theta)}{r+s}-\frac{k}{q\left(F_{3}(\tilde{y}, \psi, \theta)\right)} \geq 0
$$

We have shown $F(\tilde{y}, \psi, \theta) \in \mathcal{C}$.

$\mathcal{C}$ is a convex closed set. By definition, $\mathcal{C}$ is closed. The three first inequalities in $\mathcal{C}$ define a convex set. We have to check for the last inequality: $\mathcal{C}$ is convex if $G_{5}(\tilde{y}, \psi, \theta)=$ $\frac{\tilde{y}-\psi}{r+s}-\frac{k}{q(\theta)}$ is convex. This is true because $\theta \mapsto-\frac{1}{q(\theta)}$ is convex as long as $q$ is convex. 
$F$ has a fixed point. $F$ is continuous from the convex closed set $\mathcal{C}$ into itself. The Brouwer theorem states that $F$ has a fixed point. The corresponding equilibrium is nondegenerated as market tightness is positive and the search strategy is not the nil function.

\section{Lemma 2}

We prove the second property of lemma 2. Set $\theta$ and $\psi$ as fixed, and denote $\xi^{o}$ a solution of (5) and $\xi^{e}$ a solution of (20). Comparing (5) and (20) yields the equivalence:

$$
y(x) \leq \bar{y}\left(\xi^{e}\right) \Leftrightarrow \xi^{e}(x) \geq \xi^{o}(x)
$$

$S$ is increasing and one can prove that $S\left(\xi^{e}(x)\right)\left[y(x)-\bar{y}\left(\xi^{e}\right)\right] \leq S\left(\xi^{o}(x)\right)\left[y(x)-\bar{y}\left(\xi^{e}\right)\right]$, no matter the sign of $y(x)-\bar{y}\left(\xi^{e}\right)$. After integration,

$$
2 \int_{0}^{\frac{1}{2}} S\left(\xi^{e}(x)\right)\left[y(x)-\bar{y}\left(\xi^{e}\right)\right] d x \leq 2 \int_{0}^{\frac{1}{2}} S\left(\xi^{o}(x)\right)\left[y(x)-\bar{y}\left(\xi^{e}\right)\right] d x .
$$

By definition of $\bar{y}\left(\xi^{e}\right)$, the left-hand side is equal to 0 . It follows

$$
2 \int_{0}^{\frac{1}{2}} S\left(\xi^{o}(x)\right) \bar{y}\left(\xi^{e}\right) d x \leq 2 \int_{0}^{\frac{1}{2}} S\left(\xi^{o}(x)\right) y(x) d x
$$

and, lastly,

$$
\bar{y}\left(\xi^{e}\right) \leq \bar{y}\left(\xi^{o}\right)
$$

